\title{
Iron-citrate can induce cell senescent phenotype in human fibroblasts in vitro
}

\author{
L. Matos ${ }^{*, * *}$ and H. Almeida*
}

* Laboratório de Biologia Celular e Molecular, Faculdade de Medicina, Alameda Prof. Hernâni Monteiro, 4200-319 Porto, and IBMC - Instituto de Biologia Molecular e Celular, Universidade do Porto, Rua do Campo Alegre 823, 4150-180 Porto, Portugal

** Faculdade de Ciências da Nutrição e Alimentação, Universidade do Porto, Rua Dr. Roberto Frias, 4200-465 Porto, Portugal

almeidah@med.up.pt

After a number of replications, human diploid fibroblasts (HDFs) in culture lose the ability to divide, become insensitive to further proliferation and enter a state of replicative senescence (RS) [1]. Subcytotoxic doses of several stressful agents such as hydrogen peroxide, tertbutylhydroperoxide or ethanol, are able to cause stress-induced premature senescence (SIPS) in HDFs in vitro. Such senescent cells display many features of RS as growth arrest, senescence associated beta-galactosidase (SA beta-gal), cell enlargement and overexpression of several genes (e.g., p21, TGF beta-1,IGFBP3). During ageing, iron accumulates in several tissues in vivo, and also in senescent HDFs in vitro [2]. Due to its redox-active properties, it promotes hydroxyl radical production (Fenton reaction) and eventually leads to cell injury. Free radical reactions are known to cause the accumulation of intracellular damage resulting in ageing. Iron may thus be able to cause SIPS. The main objective of the present study was to investigate whether the exposure of HDFs to a subcytotoxic concentration of iron is able to cause SIPS.

WI-38 HDFs at early cumulative population doublings (CPDs $\leq 30$ ) were cultivated in BME with $10 \%$ BFS. Treated cells were exposed to $1 \mathrm{mM}$ iron-citrate for $24 \mathrm{~h}$, whereas control cells were submitted to identical experimental conditions in the absence of the stressful agent. Cell viability and cell proliferation were assessed by MTT assay, SA beta-gal activity was detected as already described [3] and the intracellular iron content was quantified by the BPS assay.

Treated cells presented $96 \%$ of cell survival (Fig. 1A) and increased intracellular iron levels when compared with control (Fig 1B), meaning that the dose used was not cytotoxic and that the iron was internalized by the cells. Before stress, fibroblasts presented its typical fusiform shape, however after exposure to iron-citrate cells became larger, resembling the typical senescent morphology (Fig. 2). $72 \mathrm{~h}$ after stress, cell proliferation was inhibited by $26 \%$ when compared with the control (Fig. 3A). Iron stressed cells also presented an increased percentage of cells positive for SA beta-gal (26\%) when compared with the lower percentage found for control (Fig. 3B).

As conclusion, these results show that exposure of HDFs to a sublethal dose of iron-citrate induces cell morphology changes which agree with the RS senescent phenotype, suggesting that iron-citrate can induce SIPS. Experiments regarding gene expression are already in progress in order to validate these data.

\section{References}

[1] L. Hayflick, Exp Cell Res, 37 (1965) 614.

[2] D.W. Killilea, H. Atamna, C. Liao, B.N. Ames, Antiox Redox Signaling, 5(5) (2003) 507.

[3] G.P. Dimri, X. Lee, G. Basile, M. Acosta, G. Scott, C. Roskelley, E.E. Medrano, M. Linskens, I. Rubelj, O. Pereira-Smith, M. Peacocke, J. Campisi, Proc Natl Acad Sci, 92(20) (1995) 936. 


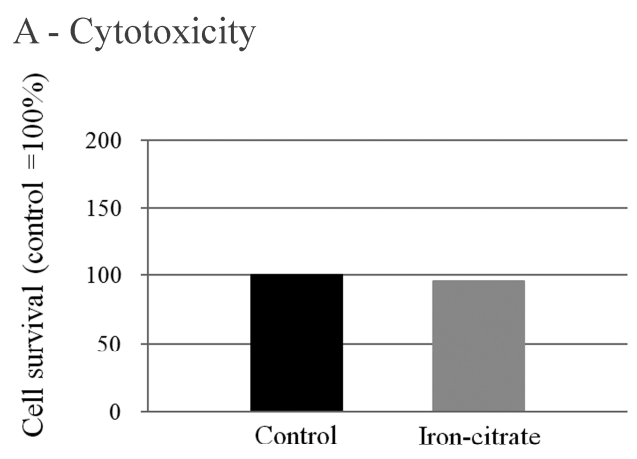

B - Intracellular iron content

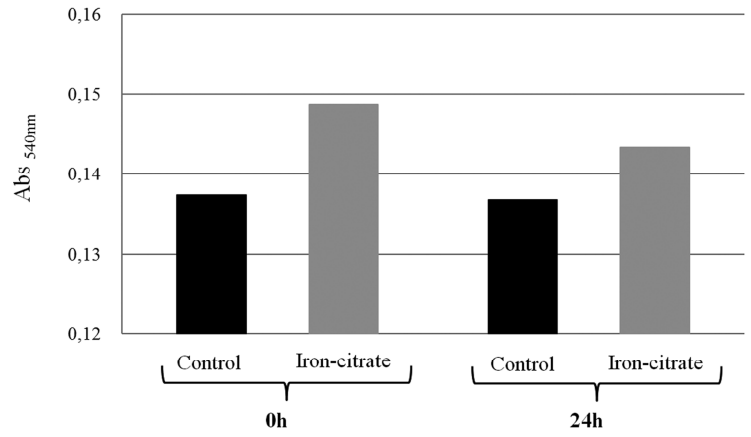

Fig. 1: Cell survival after exposure to $1 \mathrm{mM}$ Iron-citrate (A) and intracellular levels of iron 0 and $24 \mathrm{~h}$ after treatment (B).

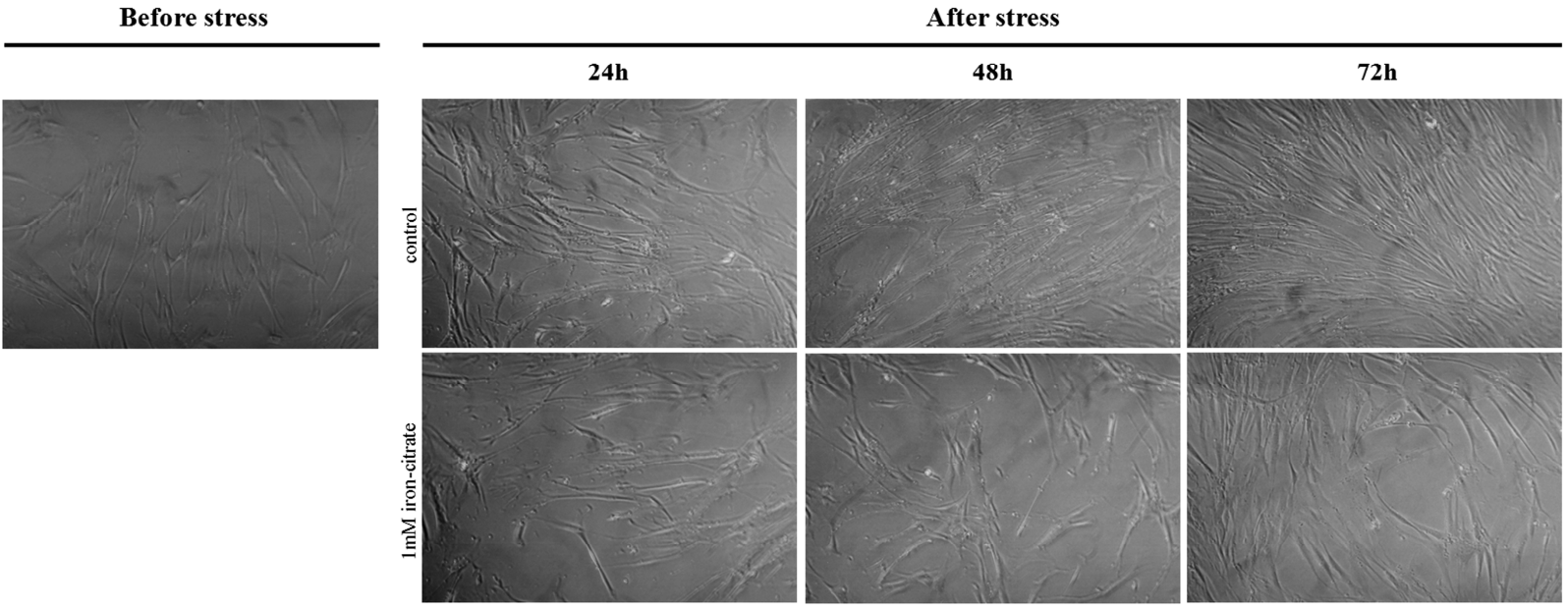

Fig. 2: Morfological changes on cell shape after exposure to $1 \mathrm{mM}$ Iron-citrate.

A - Cell proliferation

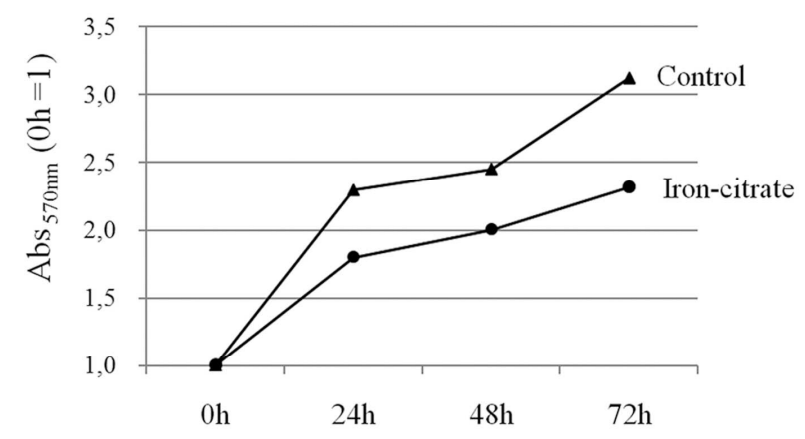

$\mathrm{B}$ - SA $\beta$-galactosidase
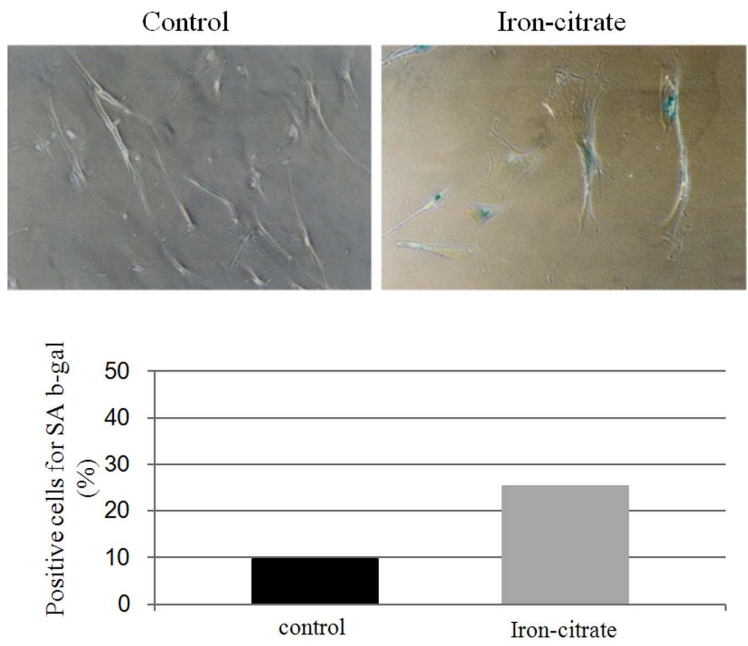

Fig. 3: Cell proliferation was inhibited $72 \mathrm{~h}$ after exposure to $1 \mathrm{mM}$ Iron-citrate (A) and the percentage of SA beta-gal activity positive cells were increased for Iron-citrate cells (B) when compared with control 